\title{
CONSIDERAÇÕES FREUDIANAS SOBRE A DINÂMICA DA LIBIDO ATRA VÉS DA TOPOGRAFIA DO APARELHO PSÍQUICO PELAS INSTÂNCIAS CONSCIENTE, PRÉ-CONSCIENTE E INCONSCIENTE
}

Teresa Cristina Martins. KOBAYASHI

*Mestranda pela Universidade Vale do Rio Verde (UNINCOR), Três Corações/Brasil; E-mail: tcmkn@hotmail.com.

Recebido em: 19/06/2012 - Aprovado em: 23/12/2012 - Disponibilizado em: 30/12/2012

Resumo: O presente artigo é o início de um estudo sobre a metapsicologia psicanalítica, um ramo da psicologia que trabalha com dados não comprovados empiricamente. Através da formulação de uma topografia do aparelho psíquico Sigmund Freud demonstra o funcionamento dinâmico das instâncias, consciente, pré-consciente e inconsciente que interagem com a pulsão da libido. Para tratarmos sobre a dinâmica da libido nas instâncias psíquicas, abordaremos os conceitos freudianos da necessidade e legitimação do inconsciente, a efetivação de uma resistência e o modo pelo qual o autor concebe a formação de uma ciência. O caso clínico apresentado tem o objetivo principal de expor os requisitos preliminares apontados por Antônio Quinet sobre as condições preliminares da análise e não servir como base de análise para o conceito da libido.

Palavras-chave: Metapsicologia. Dinâmica. Psicanálise. Conceito. Libido.

\section{CONSIDERATIONS ABOUT FREUD'S CONCEPT OF LIBIDO ACCORDING TO THE TOPOGRAPHY OF PSYCHIC APPARATUS IN CONSCIOUS, PRECONSCIOUS AND UNCONSCIOUS INSTANCES}

\begin{abstract}
The present article is the beginning of a study about psychoanalytic-meta-psychology and aims mainly to show some considerations about libido dynamics according to the topography of psychic apparatus. To discuss this dynamics between conscious, preconscious and unconscious instances, we will deal with Freud's concepts about the need and legitimation of unconscious, effectuation of resistant state and the way by which Sigmund Freud creates a science formation. The showed clinical case aims mainly to explain preliminary requirements defended by Antônio Quinet about preliminary conditions of analysis and not to be an analysis grounding for concept of libido.

Keywords: Met psychology. Dynamics. Psychoanalysis. Concept. Libido.
\end{abstract}

\section{CASO CLÍNICO ${ }^{1}$}

No momento em que fomos apresentadas na recepção pela secretária da clínica, a paciente olhou-me e com ares de sorriso disse, "há, é você”. Foi respondido cordialmente que sim, sou eu. Essa fala foi tomada pela estagiária por certa resistência expressa por "deboche" talvez de suas próprias questões pessoais, contudo naquele momento não poderia ter outra atitude se não a de firmar a postura de

\footnotetext{
${ }^{1}$ Caso clínico apresentado no ano de 2008 ao curso de psicologia como articulação teórico/prática de atendimento realizado na clínica escola de psicologia da Universidade Vale do Rio Verde pela estagiaria T.C.M.K dentro da abordagem psicanalítica.
}

uma psicóloga (ainda que estagiária) diante de sua possível paciente, pois compreendi que era o que valeria a ela naquele primeiro contato e início de trabalho.

No livro As $4+1$ condições da análise de Antonio Quinet, publicado em 2002 o psicanalista aponta um verso budista que sabiamente diz: “Como alguém poderá dizer com certeza o que Aquilo possa ser, Enquanto por si mesmo não tiver compreendido plenamente o que É?”. Nesse início de entrevistas preliminares a disponibilidade de meu olhar e da escuta para suas questões tem sido em algumas situações a resposta às suas 
indagações que comumente buscam soluções rápidas e idealizadas. $\mathrm{O}$ ato de retroceder usando pontos expostos por ela sobre suas vivências auxilia na delimitação dos ambientes e emoções resurgidas e o retroceder "junto" a ela em sua vivência começa a marcar outra "presença", não na sua história, mas em seu caminhar por esses lugares, que lhe são de tormenta. É interessante observar que as pontuações feitas à paciente, são significadas e verbalizadas por ela em sessões posteriores, talvez, por motivo de elaboração em que o "efeito" surge a posteriori e junto aos efeitos surgem novas demandas, ao que indica mais densas de serem localizadas, observadas e trabalhadas. A assiduidade da paciente permite um ritmo de trabalho próprio em que os pontos salientados em sessões causam efeitos de sonhos e irritações constantemente expressos e percebidos pelo tom irônico de suas falas. As pontuações que fazem alusão à paciente se situar em meio às vivências que ela traz é subjetivamente um questionamento implícito que lhe pergunta “quem é você?", ou ainda "o que você quer?". Em resposta aos questionamentos implícita ela traz a duvida de si mesma sobre o contexto de uma história vivenciada, contudo, a dúvida faz menção não exatamente, ao conteúdo exposto, mas à pergunta implícita anteriormente, que pôde emergir através da história exposta. A história relatada sustenta uma condição inconsciente. Em uma fala sobre "querer ficar sozinha" continha a duvida referente a "quem sou eu para ficar sozinha e não precisar do que eu tenho até então?", e mais ainda, algo do tipo "vou ficar sozinha para ficar com quem". A meu ver esse "ficar com quem" refere ao trabalho psicológico que refere antes à possibilidade se descortinar a um intermédio que lhe soa como algo estranho, sem proteção e nem promessas, mas que lhe tem ofertado à medida de sua fala certo alívio por ela mesma relatada. A partir das questões pontuadas elas começam a dar os ares de suas caras, e são apresentadas em atitudes e situações desconexas, silenciosas e que expressam singularidades do sujeito. Interpretar os sinais auxilia na identificação da demanda, dos pontos a serem trabalhados e os que possivelmente serão expostos em decorrência de um mal estar suscitados a eles. Antonio Quinet nos aponta considerações pertinentes quanto à posição do saber:

O estabelecimento da transferência é necessário para que uma análise se inicie: é o que denominamos a função das entrevistas preliminares. Mas a transferência não é condicionada nem motivada pelo analista. Ela esta aí [...]. a A transferência não é [...] função do analista, mas do analisante; a função do analista é saber utilizá-la. [...] transferência de saber: trata-se de uma ilusão na qual o sujeito acredita que sua verdade encontra-se já dada no analista e que este a conhece de antemão. [...]. Se o analista empresta sua pessoa para encarnar esse sujeito suposto saber, ele não deve de maneira alguma identificar-se com essa posição de saber que é um erro, uma equivocação. [...]. A posição de analista não e 
de saber, nem tão pouco a de compreender o paciente, pois se há algo que ele deva saber é que a comunicação é baseada no malentendido. Sua posição muito mais do que posição de saber, é uma posição de ignorância, mas não a simples ignorância ignara, mas a ignorância douta. A ignorância douta é um convite não apenas à prudência, mas também à humildade; um convite a se precaver contra o que seria a posição de um saber absoluto; contra aposição do analista de aceitar essa imputação de saber que o analisante lhe faz. O saber é, no entanto, pressuposto à função do analista. (QUINET, 2004).

\section{INTRODUÇÃO}

$\mathrm{O}$ presente artigo trata de acompanhar algumas considerações de Freud quanto à questão da libido do ponto de vista dinâmico. Para tanto é viável situar dentro da teoria psicanalítica o significado do termo "libido" bem como sua articulação em meio à topografia do aparelho psíquico.

Como forma de tornar compreensível e estruturar sua teoria, Freud criou um esboço do aparelho psíquico ao qual foi possível expressar num conjunto coordenado os diversos elementos estruturais da teoria psicanalítica. O resultado da formulação estruturada de seu material de estudo foi a metapsicologia que possibilitou através da divisão topográfica de um campo consciente, pré-consciente e inconsciente, sistematizar em delimitações imprecisas instancias denominadas de Id, Ego e Superego que se articulam em atividades psíquicas. A libido é um dos elementos, se não, o principal elemento que compõe esta atividade. (ASSOUN, 1995).

A partir da observação dos fenômenos psíquicos é possível verificar a vicissitude da libido, mostrando assim o processo inverso para a formulação de uma ciência, onde primeiro se verifica sobre a descrição do fenômeno passando para seu agrupamento, sua classificação e por ultimo sua correlação, para só então, ser possível formular conceitos sobre o tema. A proposta do aparelho psíquico não desconsidera que o avanço do conhecimento não tolera qualquer rigidez, inclusive em se tratando de definições.

\section{O INCONSCIENTE}

"Per via de porre... Per via de levare" (FREUD apud, DA VINCI). Sobre essa citação, Freud faz uma distinção máxima entre a diferença do trabalho psicanalítico e a de outras psicoterapias situando ao trabalho artístico dos pintores como uma atividade que preenche, põe elementos no caso às cores sobre o branco que nada existia enquanto que o escultor retira e encontra na pedra a escultura que já havia contida nela. Essa é a mesma diferença que existe entre a sugestão e a psicanálise, sendo que a primeira não se preocupa com a origem a força e o sentido dos sintomas patológicos que é preciso suprimir e por isso, o que faz é sobrepor ao sintoma a sugestão que terá ou não força 
suficiente para suprimir o sintoma. Em contra partida, a terapêutica psicanalítica propõe assim como o escultor trabalhar "per via de levare", extraindo os excessos. Sob essa metáfora o psicanalista se propõe a investigar a gênese dos sintomas e suas conexões com a vida patogênica, que pretende trabalhar. Situando o campo da psicanálise e concluindo que o vínculo atual existente entre a psicanálise e os métodos utilizados outrora como, por exemplo, o método catártico (hipnótico) e o método de persuasão (sugestão) é um vinculo de caráter histórico que foram como etapas para chegar à psicanálise.

Tallaferro nos aponta que o uso da associação livre realizada pelo paciente permite ao analista informar-se do que ele pensa e desvendar o elemento ou a "cadeia associativa que o levará ao nuclear". Com esse procedimento o ego não se anula, permitindo a observação dos mecanismos de defesa assim como possibilitando a realização da transferência “[...] o uso da livre associação descobre $o$ inconsciente enquanto a consciência continua atuando". (TALLARERRO, 1989).

\section{NECESSIDADE E LEGITIMAÇÃO DO INCONSCIENTE}

Sobre a justificativa da existência do inconsciente Freud (1915), aponta que a suposição da existência de algo mental e inconsciente tornou-se necessária a partir da verificação de atos psíquicos que não podiam ser explicados somente pela consciência, como os sonhos.

[...] nossa suposição a respeito do inconsciente é necessária e legitima e dispomos de numerosas provas de sua existência [...] a experiência diária mais pessoal nos tem familiarizado com ideias que assomam nossa mente e não sabemos vindas de onde, e com conclusões intelectuais que alcançamos, sem sabermos como. (FREUD, 1915).

Segundo Freud (1915) os estados psíquicos inconscientes são aqueles que se encontram por consideráveis períodos de tempo num estado latente à consciência. A suposição de um estado inconsciente torna-se legitima na medida em que a psicanálise não se afasta de indagações consoantes ao nosso próprio estado de coisas, nesse caso, as inferências consubstanciam os processos mentais que nos falham à consciência. Atribuir como hipótese, a esses atos e manifestações uma segunda ou terceira consciência seria ao menos estranho visto que seria uma consciência que nos chegaria como se fosse de outrem e seriamos assomados de tantas consciências necessárias para postular os vários estados psíquicos desconhecidos por nós e entre si. A legitimação justifica-se também pelo fato da investigação analítica do inconsciente revelar nos processos latentes características que apesar de nos parecerem estranhas vão de encontro com peculiaridades presentes na 
consciência e familiares ao sujeito. Essas constatações clínicas constatam que não há uma segunda ou terceira consciência e sim a existência de atos psíquicos que carecem de consciência para se tornarem presente à consciência.

Podemos ir além e afirmar, em apoio da existência de um estado psíquico inconsciente, que, em um dado momento qualquer, o conteúdo da consciência é muito pequeno, de modo que a maior parte do que chamamos conhecimento consciente, deve permanecer, por considerável período de tempo, num estado de latência, isto é, deve estar psiquicamente inconsciente. (FREUD, 1915).

Sobre o estado de latência Freud (1915) aponta que uma lembrança latente é um resíduo de um processo psíquico e que a não consciência é em alguns desses estados o único aspecto que os diferenciam, "O inconsciente (...), por outro lado, abrange processos tais como os reprimidos". (FREUD, 1915). Os processos reprimidos, em oposição a alguns processos psíquicos latentes, caso se tornassem conscientes, estariam propensos a sobressair num contraste mais grosseiro com o restante dos processos conscientes.

\section{SOBRE A REPRESSÃO E RESISTÊNCIA} No texto "Transferência" (FREUD, 1917), o autor aborda sobre o que se pode fazer a fim de substituir o que é inconsciente em nosso paciente por quilo que é consciente:

O nosso conhecimento acerca do material inconsciente não é equivalente ao dele; se lhe comunicarmos nosso conhecimento, ele não o receberá em lugar de seu material inconsciente, mas ao lado do mesmo; e isso causará bem poucas mudanças no paciente.

(FREUD, 1917)

E explica que se deve situar o material inconsciente topograficamente, procurar em sua memória o lugar em que se tornou inconsciente devido a uma repressão. A repressão deve ser eliminada podendo o material consciente substituir o inconsciente. "Como removemos uma repressão dessa espécie?" (FREUD, 1917). A essa altura, a tarefa entra numa segunda fase. Primeiro a busca da repressão e depois a remoção da resistência que mantém a repressão. A repressão segundo Freud, pode ser removida descobrindo-a e mostrando-a ao paciente, mas então estaremos fazendo no momento e lugar certo em processo de transferência (FREUD, 1917). A resistência deriva de uma repressão, a mesma que o analista se esforça em trabalhar, ou de uma repressão anterior, acumulada. As resistências surgem por anticatexias que reprimem o impulso censurável. A anticatexia ou a resistência, não fazem parte do inconsciente, mas do ego. Quando for facultado ao ego reconhecer as anticatexias, espera-se que essas sejam 
abandonadas. "Quais as forças motrizes que trabalhamos em um caso desses?" (FREUD, 1917).

$\mathrm{O}$ autor considera que em primeiro lugar o desejo de recuperação do paciente que o levou a um trabalho em conjunto e também o auxílio de sua inteligência à qual se fornece pontos de apoio através da interpretação.

Sobre a inteligência, Freud diz que é mais fácil a inteligência do paciente reconhecer a resistência e encontrar a tradução correspondente àquilo que está reprimido se lhe tiver fornecido previamente as ideias orientadoras apropriadas. (FREUD, 1917).

Segundo Freud em numerosas doenças nervosas, na histeria, nos estados de ansiedade, na neurose obsessiva a expectativa do analista se cumpre. Ao procurar a repressão, revelar as resistências e assinalar o que está reprimido, conseguimos, com efeito, cumprir nossa tarefa, isto é, vencer as resistências, remover a repressão e transformar o material inconsciente em material consciente. Ao fazê-lo, obtemos a mais vívida ideia da forma como uma violenta luta se trava na mente do paciente ante cada resistência a vencer. Uma luta mental, normal, no mesmo chão psicológico, entre os motivos que procuram manter a anticatexia e os motivos que estão preparados para abandonála. (FREUD, 1917).

Os "motivos" do passado, os primeiros instalaram a repressão, os novos surgiram recentemente e se espera que decidam abandonar o estado de repressão visto a decisão primeira (retensão da repressão) ter levado à doença. $\mathrm{O}$ novo caminho the soa como possibilidade de mudar de circunstâncias. Atualmente o ego tornou-se forte e experiente e tem à mão um aliado na figura revivida em direção a um resultado melhor do que aquele que levou a repressão.

Existem, entretanto, outras formas de doença nas quais, malgrado as condições sejam as mesmas a conduta terapêutica não obtêm êxito. Nelas também se tem verificado que houve um conflito entre o ego e a libido que acarretou a repressão. (FREUD, 1917). Esses pacientes - paranoicos, melancólicos, sofredores de demência precoce, permanecem, de um modo geral, intocados e impenetráveis ao tratamento psicanalítico.

\section{SOBRE A ESTRUTURAÇÃO DAS CIÊNCIAS}

No texto intitulado "Os instintos e suas vicissitudes" considerando sobre as ciências, Freud refere sobre o processo de elaboração de uma ciência: “[...] as ciências devem ser estruturadas em conceitos claros e bem definidos e que de fato, nenhuma ciência, nem mesmo a mais exata, começa com tais definições". (FREUD, 1915). Segundo o autor o início da atividade científica consiste antes na descrição dos fenômenos, passando então a seu agrupamento, sua classificação e sua correlação. Mesmo na fase de descrição não é possível evitar que se aplique certas ideias abstratas ao material manipulado. As novas observações (ideias), indispensáveis ao 
material posteriormente elaborado, se tornarão os conceitos básicos de uma ciência. A indefinição do conteúdo observado permite repetidas referências que parecem provir da compreensão acerca do significado desse material, mas de fato foram impostas a ele, são da natureza das convenções, que exige serem escolhidas por conter relações significativas com o material empírico. Relações que parecem ser sentidas antes de serem reconhecidas e determinadas claramente. A partir da investigação mais completa do campo de observação é possível formular os conceitos científicos básicos com maior exatidão, modificando-os de modo a se tornarem úteis e coerentes numa vasta área. Chegado o momento de, agora, confiná-los em definições, contudo, o avanço do conhecimento não tolera qualquer rigidez, inclusive em se tratando de definições. (FREUD, 1915).

\section{A DINÂMICA DA LIBIDO}

Segundo Freud a "Libido é um termo empregado na teoria das pulsões para descrever a manifestação dinâmica da sexualidade". (FREUD, 1922). A psicanálise cedo se deu conta de que todas as ocorrências mentais deveriam ser vistas como construídas na base de uma ação recíproca das forças das pulsões, com isso acarretou uma situação difícil, visto a psicologia não incluir nenhuma teoria das pulsões. A primeira esfera de fenômenos a ser estudada pela psicanálise compreendia o que era conhecido como neurose de transferência (histeria e neurose obsessiva). Descobriu-se que seus sintomas sucediam pelo fato de as pulsões sexuais serem rejeitadas (reprimidas) pela personalidade do sujeito (o seu ego), encontrando, pois, expressão por caminhos tortuosos através do inconsciente.

\section{FIGURA I - EXEMPLO DE AÇÃO RECÍPROCA DE FORÇAS: PRIMEIRAS FORMULAÇÕES DAS PULSÕES}

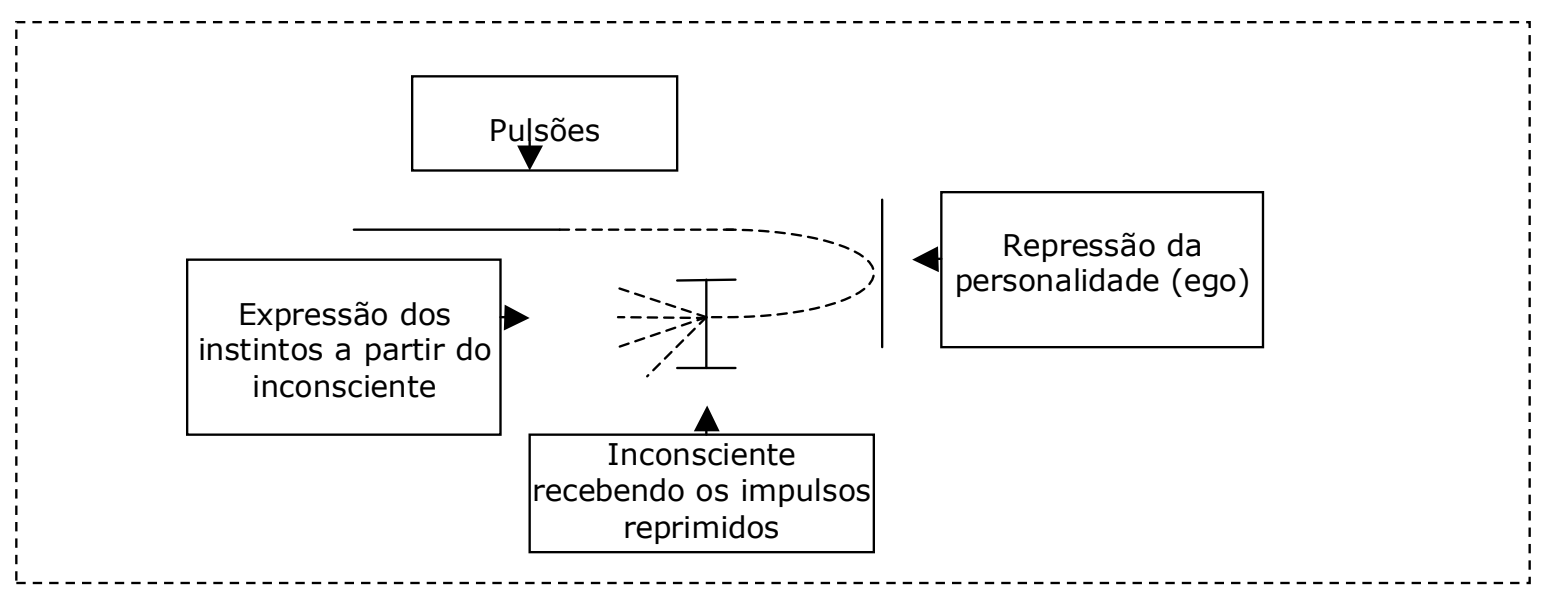

Esses fatos podiam ser traçados num contraste entre as pulsões sexuais e as pulsões do ego (pulsões de autopreservação), o que estava de acordo com o dito popular de serem 
a fome e o amor que fazem o mundo girar: a libido era a manifestação da força do amor, no mesmo sentido que a fome o era da pulsão de autopreservação. Com o estudo da demência precoce e outros distúrbios psicóticos, a partir do ego descobre-se que o processo patogênico na demência precoce é acometido pela retirada da libido dos objetos acomodando-os no ego, assim os sintomas clamorosos da moléstia surgem dos vãos esforços da libido para encontrar um caminho de volta aos objetos. Mostrou-se com essa proposição ser possível à libido de objeto transformar-se em catexia do ego e vice-versa. O ego passa a ser compreendido como um reservatório de libido, do qual a libido é enviada para os objetos que sempre está pronto para absorver a libido que flui de volta dos objetos. As pulsões de autopreservação também eram de natureza libidinal: eram pulsões sexuais que em vez de objetos externos haviam tomado o próprio eu do sujeito como objeto.

A experiência clínica mostrou-nos com as pessoas que comportam de uma maneira notável, como se estivessem enamoradas de si mesmas, e essa perversão recebeu o nome de narcisismo. (FREUD, 1922)

A libido das pulsões de autopreservação foi então descrita como libido narcísica e reconheceu-se que um elevado grau desse auto-amor constituía o estado de coisa primária e normal. As pulsões sociais pertencem a uma classe de pulsões que são descritas como sublimadas, embora estejam estreitamente relacionadas as pulsões narcísicas, não abandonaram seus objetivos diretamente sexuais, mas são impedidas, por resistências internas, de alcançarem um fim sexual, contentam-se com certas aproximações à satisfação e, por essa própria razão, conduzem a ligações especialmente firmes e permanentes entre os seres humanos.

\section{LIBIDO DO PONTO DE VISTA BIOLÓGICO SEGUNDO FREUD}

Embora a psicanálise via de regra se esforce por desenvolver suas teorias tão independentemente quanto possível das outras ciências, é, contudo, obrigada a procurar uma base para a teoria das pulsões na biologia (FREUD, 1922). Houve na teoria psicanalítica o reconhecimento de duas classes de pulsões correspondentes aos processos contrários de construção e dissolução no organismo. Segundo esse ponto de vista, um dos conjuntos de pulsões, que trabalham essencialmente em silêncio, seria aquele, cujo objetivo é conduzir a criatura viva à morte e, assim, merecem ser chamados de "pulsão de morte", dirigir-se-iam para fora como resultado da combinação de grande número de organismos elementares unicelulares e se manifestariam como impulsos destrutivos ou agressivos. O outro conjunto de pulsão é a quele que são mais bem conhecidos na análise: as "pulsões libidinais sexuais" ou "pulsão de vida" que são bem abrangidas pelo 
nome de Eros. Seu intuito seria constituir a substância viva em unidades cada vez maiores, de maneira que a vida possa ser prolongada e conduzida a uma evolução mais alta. "As pulsões eróticas e as pulsões de morte estariam presentes nos seres vivos em misturas ou fusões regulares, mas "difusões" também estariam sujeitas a ocorrer". (FREUD, 1922). A vida constituiria nas manifestações do conflito ou na interação entre as duas classes de pulsão. A morte significaria para a vitória das pulsões destrutivas e a reprodução como símbolo de laço afetivo representa a vitória de Eros. A proposição biológica da natureza das pulsões permite caracterizar as pulsões como tendências inerentes à substância viva. Uma concepção historicamente determinada de natureza conservadora podendo dizer ser a expressão da elasticidade do que é orgânico. (FREUD, 1922). Ambas as classes de instinto, segundo esse ponto de vista, teriam operado e trabalhado um contra o outro, desde a primeira origem da vida.

\section{TENDÊNCIAS DA LIBIDO}

O que se descreve como pulsão sexual mostra ser de uma natureza altamente complexa e sujeita a decompor-se novamente em suas pulsões componentes. (FREUD, 1922). Cada pulsão componente é inalteravelmente caracterizada por sua fonte, isto é, pela região ou zona do corpo da qual sua excitação se deriva. Cada um deles possui, ademais, como aspectos distinguíveis um objeto e um objetivo. O objetivo é sempre a descarga acompanhada pela satisfação, mas é capaz de ser mudado da atividade para a passividade. $\mathrm{O}$ objeto acha-se menos estreitamente ligado ao instinto do que se supôs a princípio, é facilmente trocado por outro (permutável) e, além disso, uma pulsão que possuía um objeto externo pode ser voltada para o próprio eu do sujeito. As pulsões separadas podem permanecer independentes umas das outras, ou combinar-se e fundir-se umas com as outras, para realizar um trabalho em comum. Podem também substituir-se mutuamente e transferir sua catexia libidinal umas para as outras, de forma que a satisfação de uma determinada pulsão pode assumir o lugar da satisfação de outras. A vicissitude mais importante que uma pulsão pode experimentar parece ser a sublimação, aqui, tanto o objeto quanto o objetivo são modificados o que originalmente era uma pulsão sexual encontra satisfação em alguma realização que não é mais sexual, mas de uma valoração social ou ética superior. (FREUD, 1922).

\section{TIPOS DE LIBIDO}

Considerando a predominância de libido nas instâncias do aparelho psíquico é possível distinguir três tipos principais de libido. (FREUD, 1923). A "libido erótica" é aquela cujo principal interesse (parte relativamente maior da libido) está voltada para o amor. Amar e acima de tudo ser amado. Esses sujeitos são dominados pelo temor da perda do amor, podendo ser caracterizados como 
dependentes daqueles que podem retirar seu amor. Um tipo comum, mesmo em formas mais puras. Do ponto de vista cultural e social representam as exigências elementares do "id". O tipo obsessivo distingue pela predominância do superego que se separa do ego sobre grande tensão. São pessoas dominadas pelo temos de sua consciência, não apresentam tanto medo de perder o amor. Tendem a uma dependência interna ou invés de externa. São autoconfiantes e do ponto de vista social são verdadeiros e conservadores veículos da civilização. O "narcísico", terceiro tipo é descrito em termos negativos. Não há tensão entre o ego e o superego e nem preponderância de necessidades eróticas. A autopreservação é o principal interesse desse tipo de indivíduo, é independente e não tímido. O ego dispõe de quantia significativa de agressividade e manifesta presteza em suas atividades. Prefere amar a ser amado. Impressionam podendo ser vistos como personalidades apropriadas há atuarem como apoio a outros. (FREUD, 1923). O autor ainda nos aponta que os tipos mistos são observados com mais frequência do que os puros. O erótico obsessivo parece restringir a vida pulsional pela influência do superego. $\mathrm{O}$ erótico narcísico é possivelmente o mais comum. Ele une opostos que se moderam mutuamente. Já o narcísico obsessivo do ponto de vista cultural, produz a mais valiosa variação. Soma a independência do externo à exigência da consciência produzindo ação vigorosa. Nesses indivíduos o ego é fortalecido contra o superego.

Vimos nesse início de estudo que a metapsicologia, área que ocupa de aspectos não empíricos, possibilitou Freud, estruturar seus estudos a partir da configuração de uma topografia ao aparelho psíquico formado por uma instancia consciente, pré-consciente e inconsciente que dinamizam entre pulsões e forças psíquicas. O conceito de libido é apresentado como sendo pulsão antagônica inerente ao humano. Que busca satisfação podendo tanto investir como desinvestir o mesmo objeto. Seu antagonismo encontra "razão" em sal própria função pulsional que repele a satisfação já exaurida retomando sua condição primordial de pulsar e novamente investir, para numa revelia por unir-se ao diferente retoma a si. Na mitologia Eros é descrito por Platão como filho de Poro (Expediente) e Pínia (Pobreza), logo a essência do amor será "sentir falta de", numa busca constante, destinado à perpétua insatisfação. Mesmo tomando de empréstimo símbolos da mitologia e por vezes alçando mão às disposições biológicas o psicanalista prescinde a teoria na dinâmica das instâncias psíquicas realizada numa interação "econômica" de forças. A predominância da libido em certas regiões do aparelho psíquico caracteriza os tipos de libido, estes, são percebidos em geral por características singulares do sujeito o que não revela no todo de sua formação, sua profundidade e formas de articulação em meio à topografia do 
aparelho psíquico. $\mathrm{O}$ ato de deslocar e sublimar a libido levando em uma satisfação já não mais sexual e sim um valor ético e social mais elevado demonstra a capacidade de permutação e satisfação equivalente da libido.

\section{REFERÊNCIAS BIBLIOGRÁFICAS}

FREUD, Sigmund. Linhas de Progresso da Teoria Psicanalítica. Imago: Rio de Janeiro, Edição Standard Brasileira das Obras Psicológicas Completas de Sigmund Freud.

------ (1905) "A Teoria da Libido".

------ (1914) "Os Instintos e Suas

Vicicitudes”.

------ (1915) "O inconsciente".

------ (1915) "Artigos Sobre a

Metapsicologia”.

------ (1917) "Teoria da Libido e Narcisism".

------- (1917) "Transferência".

------ (1920) "Sugestão e Libido".

------ (1920) "O Instinto Gregário".

-------(1923) "O Grande Reservatório da

Libido".

------ (1927) “Tipos Libidinais”.

ASSOUN, Paul Laurent, Metapsicologia

freudiana: Uma introdução: Zahar. Rio de Janeiro, 1995.

TALLAFERRO, Alberto, Curso básico de psicanálise: Martins Fontes. São Paulo, 1989.

QUINET, Antônio, As 4 + 1 condição da análise: Zahar: Rio de Janeiro, 2000.
Complexa, extremamente viva ainda que presente na pulsão de morte a libido se transporta na condição de força psíquica num organismo vivo. 